\title{
Dropper Bottle
}

National Cancer Institute

\section{Source}

National Cancer Institute. Dropper Bottle. NCI Thesaurus. Code C43171.

A bottle that has a device specifically intended for the application of a liquid in a drop by drop manner, or a device intended for the delivery of an exact dose (e.g., calibrated dropper for oral medications). 